\title{
Stereotactic body radiation therapy for patients with heavily pretreated liver metastases and liver tumors
}

\section{Rachelle Lanciano*, John Lamond, Jun Yang, Jing Feng, Steve Arrigo, Michael Good and Luther Brady}

Philadelphia CyberKnife, Drexel University, Havertown, PA, USA

Edited by:

Sean Collins, Georgetown University Hospital, USA

\section{Reviewed by:}

Dalong Pang, Georgetown University Hospital, USA

Keith Unger, Georgetown University, USA

\section{*Correspondence:}

Rachelle Lanciano, Philadelphia

CyberKnife, Drexel University, 2010

West Chester Pike, Suite 115,

Havertown, PA, USA.

e-mail: rlancmd@gmail.com
We present our initial experience with CyberKnife stereotactic body radiation therapy (SBRT) in a heavily pretreated group of patients with liver metastases and primary liver tumors. From October 2007 to June 2009, 48 patients were treated at the Philadelphia CyberKnife Center for liver metastases or primary liver tumors. We report on 30 patients with 41 discrete lesions (1-4 tumors per patient) who received an ablative radiation dose (BED $\geq 79.2 \mathrm{~Gy} 10=66 \mathrm{~Gy}$ EQD2). The treatment goal was to achieve a high SBRT dose to the liver tumor while sparing at least $700 \mathrm{cc}$ of liver from radiation doses above $15 \mathrm{~Gy}$. Twenty-three patients were treated with SBRT for metastatic cancer to the liver; the remainder $(n=7)$ were primary liver tumors. Eighty-seven percent of patients had prior systemic chemotherapy with a median 24 months from diagnosis to SBRT; 37\% had prior liver directed therapy. Local control was assessed for 28 patients (39 tumors) with 4 months or more follow-up. At a median follow-up of 22 months (range, 10-40 months), 14/39 (36\%) tumors had documented local failure. A decrease in local failure was found with higher doses of SBRT ( $p=0.0237) ; 55 \%$ of tumors receiving a BED $\leq 100$ Gy10 (10/18) had local failure compared with $19 \%$ receiving a BED > $100 \mathrm{~Gy} 10$ (4/21). The 2-year actuarial rate of local control for tumors treated with BED > $100 \mathrm{~Gy} 10$ was $75 \%$ compared to $38 \%$ for those patients treated with BED $\leq 100$ Gy $10(p=0.04)$. At last follow-up, 22/30 patients ( $73 \%)$ had distant progression of disease. Overall, seven patients remain alive with a median survival of 20 months from treatment and 57 months from diagnosis. To date, no patient experienced persistent or severe adverse effects. Despite the heavy pretreatment of these patients, SBRT was well tolerated with excellent local control rates when adequate doses (BED > 100 Gy10) were used. Median survival was limited secondary to development of further metastatic disease in the majority of patients.

Keywords: liver metastases, stereotactic body radiation therapy, hepatocellular carcinoma and cholangiocarcinoma

\section{INTRODUCTION}

The treatment of liver metastases and primary liver tumors has evolved with surgery as the current standard of care for localized lesions in medically operable patients (Robertson et al., 2009). Some patients with extensive liver metastasis at presentation can become surgical candidates following chemotherapy, as improved drugs with better response rates have been developed (Adam et al., 2009). However, only a limited proportion of liver metastases patients (10-20\%) can ultimately undergo surgical resection because of associated comorbidities, age, disease extent, and patient wishes.

Alternative liver directed treatment approaches for unresectable liver metastases and primary liver tumors include radiofrequency ablation, cryotherapy, and chemoembolization. These techniques have selection criteria which limit eligibility such as size, location, and number of tumors (Kemeny, 2006). Stereotactic body radiation therapy (SBRT) is used to deliver ablative doses of radiation to an extracranial target with high precision and rapid fall-off that spares surrounding tissues. Early SBRT results revealed excellent tolerance and local control rates for liver metastases and primary liver tumors (Hoyer et al., 2006; Mendez Romero et al., 2006; Wulf et al., 2006; Lee et al., 2009; Rusthoven et al., 2009). The CyberKnife system (Accuray Inc., Sunnyvale, CA, USA) has several features that make it well suited for liver SBRT. Radiation delivery is performed by a linear accelerator mounted on a robotic arm that accurately aligns and delivers the radiation in the form of hundreds of "beamlets" which allows optimization of the tumor dose while sparing surrounding normal tissue. In addition, the CyberKnife's Synchrony motion tracking system, which uses real-time imaging and fiducial tracking, improves targeting accuracy because of the ability to track the tumor, and adjust the beam during respiration (Kilby et al., 2010). With better accuracy, tighter margins and higher doses are possible. Initial reports on CyberKnife SBRT for liver tumors have shown promising local control with minimal toxicity for select patients with hepatocellular carcinoma (HCC; Choi et al., 2008; Louis et al., 2010), metastases (Ambrosino et al., 2009; Stintzing et al., 2010), and mixed populations of both HCC and metastases (Goodman et al., 2010).

In this report we describe our initial experience with CyberKnife SBRT in a heavily pretreated group of patients with liver metastases and primary liver tumors with regard to SBRT technique and outcome. 


\section{MATERIALS AND METHODS PATIENTS}

From October 2007 to June 2009, 48 patients were treated at the Philadelphia CyberKnife Center for liver metastases or primary liver tumors. Patients were divided into ablative (BED $\geq 79.2$ Gy10 equivalent to $2 \mathrm{~Gy} \times 33,12 \mathrm{~Gy} \times 3$, or $8.5 \mathrm{~Gy} \times 5)$ and nonablative (BED $<79.2$ Gy10) populations. The BED was calculated as $\mathrm{BED}=D *(1+d / \alpha / \beta)$ where $D$ is the total dose, $d$ is the dose per fraction and the $\alpha / \beta$ ratio for the tumor was $10 \mathrm{~Gy}$. The total biologically equivalent dose in 2 Gy fractions, EQD2, was calculated as $\mathrm{EQD} 2=\mathrm{D} *[(d+\alpha / \beta) /(2 \mathrm{~Gy}+\alpha / \beta)]$. An ablative dose regimen was defined as at least $66 \mathrm{~Gy}$ in $2 \mathrm{~Gy}$ per fraction $(\mathrm{EQD} 2=66 \mathrm{~Gy}$ ) based on conventional fractionation. For this IRB approved retrospective study, only those patients treated with an ablative dose of radiation (BED $\geq 79.2$ Gy10) were further studied and reported. No patient had impaired liver function or more than four discrete lesions.

\section{TREATMENT}

Stereotactic body radiation therapy was delivered using the CyberKnife system (Accuray Incorporated, Sunnyvale, CA, USA) with $6 \mathrm{mV}$ photons. Multiplan software was used for treatment planning. All patients had one to three gold fiducial markers placed under CT guidance within each tumor for tracking during treatment. Triple phase contrast enhanced CT was obtained for treatment planning 7-10 days following fiducial placement. Liver windows with contrast were usually used for contouring the clinical target volume (CTV), however, on occasion the liver metastases were more visible on liver windows without contrast so both were obtained in each patient. In addition to the liver tumor/metastases (CTV), normal tissues in proximity to the tumor were contoured including the bowel, heart, rib, and kidney. Normal tissue dose constraints were applied as defined by Timmerman (2008). The entire liver was contoured in all patients and the tumor volume subtracted for dose volume histogram analysis. The gross target volume (GTV) equaled the CTV. The planning target volume was defined by a uniform $5 \mathrm{~mm}$ CTV expansion. If necessary, due to normal tissue proximity, margins were reduced to $3 \mathrm{~mm}$ or less. Dose was generally prescribed to the $60-80 \%$ isodose line to cover $95 \%$ of the PTV with the prescribed dose. Both isocentric and nonisocentric treatment plans were used depending on patient specific variables (liver size and tumor shape). However, non-isocentric treatment plans were used in the majority of patients. Treatment was delivered using between 80 and 150 beams. Synchrony tracking was utilized in all patients to account for respiratory movement of the tumor by tracking the fiducials throughout the respiratory cycle. During treatment, tracking images were taken every three beams.

\section{FOLLOW-UP AND STATISTICAL ANALYSIS}

Patients were generally seen at 1 and 3 months after treatment and every 6 months thereafter. Acute toxicities were defined as those occurring within 3 months of treatment. All toxicities were graded using the Radiation Therapy Oncology Group (RTOG) scoring system (Cox et al., 1995). PET/CT, CT, or MRI imaging was obtained at 3-6 months follow-up to assess local control. For HCC CT or MRI was preferred. The RECIST 1.1 (Therasse et al.,
2000) and PERCIST 1.0 (Wahl et al., 2009) criteria were used to define local failure depending on the availability of PET/CT. In either case, each lesion was evaluated independently if more than one lesion was treated per patient. In the absence of PET/CT, local failure was defined as $\geq 5 \mathrm{~mm}$ net increase in the target lesion's longest diameter (Therasse et al., 2000); otherwise (preferred) local failure was defined as a persistently metabolically active mass or recurrence of metabolic activity with a maximum SUV above liver background activity. Pretreatment PET/CT with a metabolically active target lesion was required for PET/CT evaluation (Wahl et al., 2009). Unpaired $t$-tests and chi-squared analysis were used to assess statistical significance. Kaplan-Meier local control and survival analysis was performed.

\section{RESULTS}

\section{PATIENTS}

The 30 patients treated with an ablative SBRT dose (BED $\geq 79.2$ Gy10) had 41 discrete lesions (range 1-4 tumors per patient). The majority of patients were treated for liver metastases $(n=23)$ with the rest either cholangiocarcinoma $(n=4)$ or HCC $(n=3)$. Median age of all patients was 64 years (range $47-$ 89 ). The patients were heavily pretreated. Eighty-seven percent of patients $(n=26)$ had prior systemic chemotherapy for treatment of liver metastases or liver tumor. Thirty-seven percent of patients $(n=11)$ had prior liver directed therapy which included surgical resection, chemoembolization, radiofrequency ablation, photodynamic therapy, or previous external beam radiation with four patients having more than one prior liver directed treatment. The median time from diagnosis to SBRT for all patients was 26 months (range, 1-95 months). Patient characteristics are summarized in Table 1.

\section{TREATMENT FACTORS}

The treatment planning goal was to spare at least $700 \mathrm{cc}$ of uninvolved liver from doses of radiation greater than $15 \mathrm{~Gy}$ to maintain hepatic function (Schefter et al., 2005). Thus, the pretreatment liver and tumor volumes were important factors determining prescribed dose as detailed in Table 1. Median pretreatment liver volume was $1464 \mathrm{cc}$ (range 907-2450 cc). Median volume of liver receiving $\leq 15 \mathrm{~Gy}$ was $1142.5 \mathrm{cc}$ (range 662.2$2000.1 \mathrm{cc}$ ) Patients with previous liver directed therapy had a lower median pretreatment liver volume and median volume of liver receiving $\leq 15 \mathrm{~Gy}$ compared to those patients with no previous liver directed therapy. Radiation doses ranged from $12 \mathrm{~Gy} \times 3 \mathrm{fx}(\mathrm{BED}=79.2 \mathrm{~Gy} 10, \mathrm{EQD} 2=66 \mathrm{~Gy})$ to $20 \mathrm{~Gy} \times 3 \mathrm{fx}$ $(\mathrm{BED}=180 \mathrm{~Gy} 10, \mathrm{EQD} 2=150 \mathrm{~Gy})$ with the most common fractionation being $12.5 \mathrm{~Gy} \times 3 \mathrm{fx}(\mathrm{BED}=84.4 \mathrm{~Gy} 10, \mathrm{EQD} 2=70 \mathrm{~Gy})$ prescribed to the $60-80 \%$ isodose line to cover $95 \%$ of the PTV. Over half of the patients had PET/CT for local control assessment with $79 \%$ of local failures documented by PET/CT (Table 2 ). Figure 1 shows the SBRT dose distribution and corresponding response as assessed by PET/CT of a patient who received sequential courses of CyberKnife SBRT to two hepatic metastases.

\section{CLINICAL OUTCOMES}

At 22 months (range, 10-40 months) median follow-up, 14 (36\%) of the 39 tumors in the 28 patients with more than 4 months 
Table 1 | Patient characteristics and treatment parameters.

\begin{tabular}{|c|c|c|}
\hline Patients & 30 & \\
\hline Lesions & 41 & \\
\hline \multicolumn{3}{|l|}{ Age } \\
\hline Median & 64 & \\
\hline Range & $47-89$ & \\
\hline Liver lesions per patient & Number & Percent \\
\hline 1 & 22 & 73 \\
\hline 2 & 6 & 20 \\
\hline 3 & 1 & 3.33 \\
\hline 4 & 1 & 3.33 \\
\hline \multicolumn{3}{|l|}{ Primary liver malignancy $(n=7)$} \\
\hline Cholangiocarcinoma & 4 & 13.33 \\
\hline Hepatocellular carcinoma & 3 & 10.00 \\
\hline \multicolumn{3}{|l|}{ Metastatic disease $(n=23)$} \\
\hline Colorectal cancer & 15 & 50.00 \\
\hline Breast cancer & 3 & 10.00 \\
\hline Esophageal cancer & 1 & 3.33 \\
\hline Gastrointestinal stromal tumor & 1 & 3.33 \\
\hline Pancreatic cancer & 1 & 3.33 \\
\hline Non-small cell lung cancer & 2 & 6.67 \\
\hline \multicolumn{3}{|l|}{ Previous systemic therapy } \\
\hline Yes & 26 & 86.67 \\
\hline No & 1 & 3.33 \\
\hline Unknown & 3 & 10.00 \\
\hline \multicolumn{3}{|l|}{ Previous liver directed therapy } \\
\hline Yes & 11 & 36.67 \\
\hline No & 19 & 63.33 \\
\hline Surgical resection & 2 & 6.67 \\
\hline Chemoembolization (CE) & 2 & 6.67 \\
\hline Surgical resection, RFA & 2 & 6.67 \\
\hline Radiofrequency ablation (RFA) & 1 & 3.33 \\
\hline Radiation therapy & 1 & 3.33 \\
\hline CE, RFA & 1 & 3.33 \\
\hline Surgical resection, CE, RFA & 1 & 3.33 \\
\hline Photodynamic therapy (PDT) & 1 & 3.33 \\
\hline Pretreatment liver volume (cc) & Median & Range \\
\hline All patients & 1464 & $907.8-2450$ \\
\hline Previous liver directed therapy & 1346.4 & $1118-2253$ \\
\hline No previous liver directed therapy & 1638.4 & $907.8-2450$ \\
\hline \multicolumn{3}{|l|}{ Pretreatment tumor volume (cc) } \\
\hline All tumors & 25.33 & $0.534-316$ \\
\hline Largest per patient & 46.85 & $1.77-316$ \\
\hline \multicolumn{3}{|l|}{$\begin{array}{l}\text { Pretreatment median total per patient } \\
\text { tumor volume (cc) }\end{array}$} \\
\hline All patients & 60.9 & $2.29-316$ \\
\hline Previous liver directed therapy & 60.7 & $10.3-201.7$ \\
\hline No previous liver directed therapy & 61.2 & $2.29-316$ \\
\hline \multicolumn{3}{|l|}{ Volume of liver receiving $\leq \mathbf{1 5} \mathrm{Gy}$ (cc) } \\
\hline All patients & 1142.5 & $662.2-2000.1$ \\
\hline Previous liver directed therapy & 1041.4 & $662.2-1901.9$ \\
\hline No previous liver directed therapy & 1215.3 & $689.0-2000.1$ \\
\hline Prescribed Dose (BED) & Number & Percent \\
\hline 12 Gy × 3 (79.2 Gy10, EQD2 = 66 Gy) & 2 & 6.67 \\
\hline 12.5 Gy × 3(84.38 Gy10, EQD2 = 70 Gy) & 17 & 56.67 \\
\hline
\end{tabular}

(Continued)

\begin{tabular}{lll}
\hline $10 \mathrm{~Gy} \times 5(100 \mathrm{~Gy} 10, \mathrm{EQD} 2=84 \mathrm{~Gy})$ & 1 & 3.33 \\
$14 \mathrm{~Gy} \times 3(100.8 \mathrm{~Gy} 10, \mathrm{EQD} 2=84 \mathrm{~Gy})$ & 3 & 10.00 \\
$15 \mathrm{~Gy} \times 3(112.5 \mathrm{~Gy} 10, \mathrm{EQD} 2=94 \mathrm{~Gy})$ & 10 & 30.00 \\
$17.5 \mathrm{~Gy} \times 3(144.4 \mathrm{~Gy} 10, \mathrm{EQD} 2=120 \mathrm{~Gy})$ & 4 & 13.33 \\
$20 \mathrm{~Gy} \times 3(180 \mathrm{~Gy} 10, \mathrm{EQD} 2=150 \mathrm{~Gy})$ & 4 & 13.33 \\
$\begin{array}{l}\text { Treatment planning } \\
\text { Isocentric }\end{array}$ & 13 & 31.70 \\
Non-isocentric & 28 & 68.30 \\
\hline
\end{tabular}

Table 2 | Summary of the follow-up imaging performed denoting the imaging modality used in the assessment of the $\mathbf{1 4}$ local failures.

\begin{tabular}{lll}
\hline & Number of tumors & Percent \\
\hline FOLLOW-UP IMAGING & & \\
PET/CT & 22 & 54 \\
CT & 13 & 32 \\
MRI & 3 & 7 \\
PET/CT, MRI & 2 & 5 \\
SurgerY & 1 & 2 \\
LOCAL FAILURE EVALUATION & \\
PET/CT & 11 & 79 \\
CT & 3 & 21 \\
\hline
\end{tabular}

follow-up had local failure. Median time to local failure from SBRT was 13 months (range, 6-21 months). One- and two-year actuarial local control rates are 92 and 56\%, from time of SBRT (Figure 2A). The 2-year actuarial rate of local control for tumors with a CTV of $\leq 25.3 \mathrm{cc}$ was $57 \%$ compared to $52 \%$ for those patients with a CTV of $>25.3 \mathrm{cc}$ (Figure 2B). A decrease in local failure was found with higher SBRT dose $(p=0.0237) ; 55 \%$ of the tumors receiving a $\mathrm{BED} \leq 100 \mathrm{~Gy} 10(10 / 18)$ had local failure compared with $19 \%$ treated with a BED > 100 Gy10 (4/21). The 2-year actuarial rate of local control for tumors treated with BED $>100$ Gy10 was $75 \%$ compared to $38 \%$ for those patients treated with $\mathrm{BED} \leq 100$ Gy10 (Figure 2C, $p=0.04$ ). Distant disease progression included all failures outside the treatment volume including distant liver sites. Twenty-two of 30 patients (73\%) had distant disease progression at last follow-up, with distant failure the most common pattern of failure.

Seven $(23 \%)$ patients remain alive with a median 20 months survival from SBRT and 57 months from diagnosis. One-, two-, and three-year actuarial survival rates are 73,31 , and $17 \%$ from SBRT (Figure 3A). Given the heavily pretreated population, actuarial survival from diagnosis is also presented. Three-, five-, and seven-year actuarial survival rates are 73,44 , and $25 \%$ from diagnosis (Figure 3B). The 1-year actuarial rate of overall survival for those patients with a largest CTV $\leq 46.85 \mathrm{cc}$ was $86 \%$ compared to $60 \%$ for those with a largest CTV $>46.85 \mathrm{cc}$ (Figure 3C). At 2 years this difference was less (35 vs $26 \%$, $p=0.0899$ ). The 2 -year actuarial rate of overall survival for those patients treated with a BED $\leq 100$ Gy10 was $21 \%$ compared to $42 \%$ for those treated with a BED $>100 \mathrm{~Gy} 10$, not statistically significant (Figure 3D). At 3 years this difference was less (14 vs. $16 \%)$. 


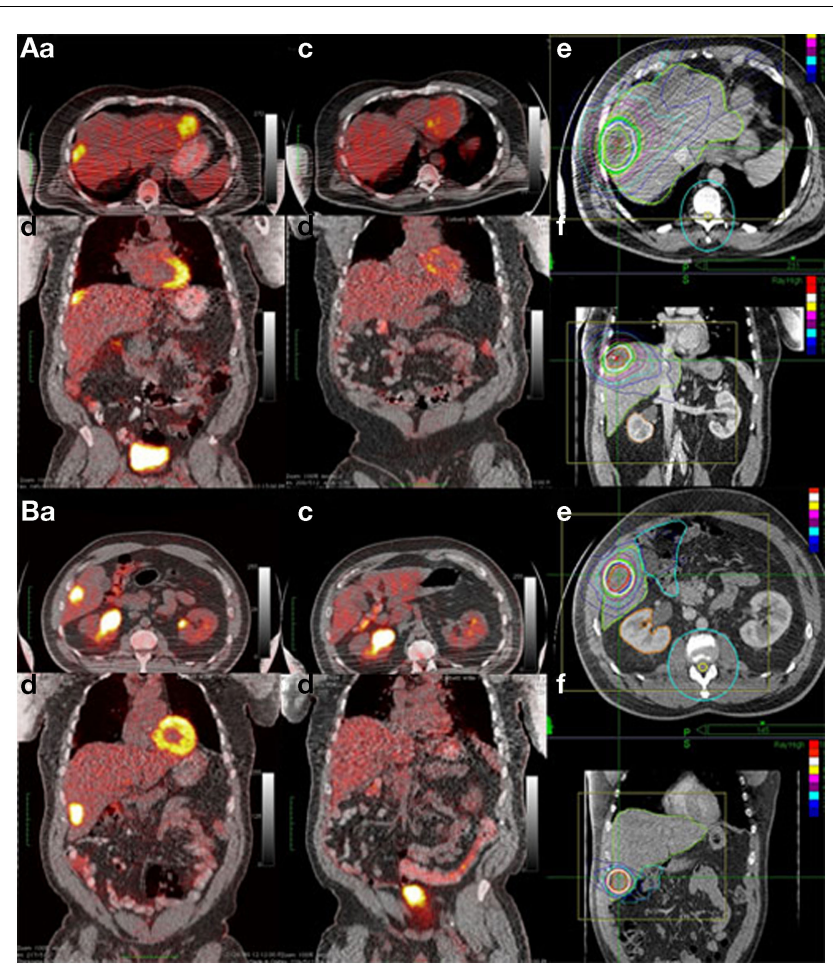

FIGURE 1 | Example of complete response to SBRT assessed by PET/CT. A 63-year-old African American male with two metachronous liver metastases 4 years after colon resection (T3N0 adenocarcinoma). He received 2 years of chemotherapy for the liver metastases with progression and was referred for SBRT. (A) Tumor 1 and (B) tumor 2. Shown in each panel are the (a) axial and (b) coronal views of the pretreatment PET/CT; the (c) axial and (d) coronal views of the post-treatment PET/CT and the (e) axial and coronal treatment planning CT denoting the SBRT dose distribution.

Treatment was well tolerated by all patients with no observed acute toxicities and minimal late toxicities observed. One patient with a solitary liver metastasis (CTV $141 \mathrm{cc}$ ) developed a grade 3 small bowel obstruction 5 months after SBRT. Following resection, pathology revealed poorly differentiated metastatic adenocarcinoma involving the small bowel mesentery and abdominal wall along with separate specimens from the abdominal wall and umbilical hernia. One patient with a large gastrointestinal stromal tumor (CTV $123 \mathrm{cc}$ ) developed a grade 2 liver abscess in the treatment volume 16 months after receiving SBRT of 37.5 Gy in 3 fractions. Hospitalization, drainage catheter and antibiotics were required. This patient's most recent CT demonstrated progression of disease outside the treated mass with continued abscess within the treated mass and was coded as a local failure by size criteria. Both patients had local/regional failure that could have accounted for the presumed complications. One patient with a solitary liver metastasis adjacent to ribs (CTV $10 \mathrm{cc}$ ) experienced pain with a grade 4 rib fracture 19 months after treatment with no evidence of local failure. Retrospective dose calculation to adjacent ribs revealed $9.5 \mathrm{cc}$ of total rib volume received over $30 \mathrm{~Gy}$.

One patient received treatment for a new liver metastasis 9 months after initial SBRT and one patient was retreated for local failure 22 months after initial SBRT; both patients' second courses
A

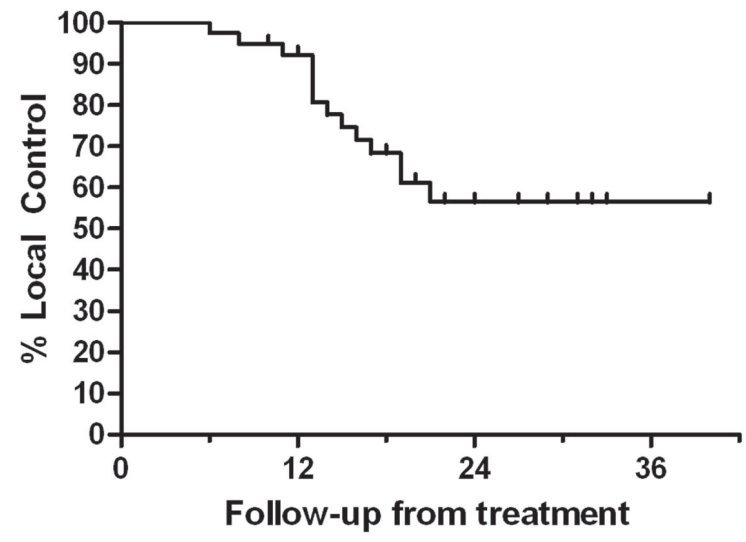

\# tumors

$\begin{array}{llllllll}\text { at risk } & 39 & 39 & 34 & 21 & 10 & 6 & 3\end{array}$

B

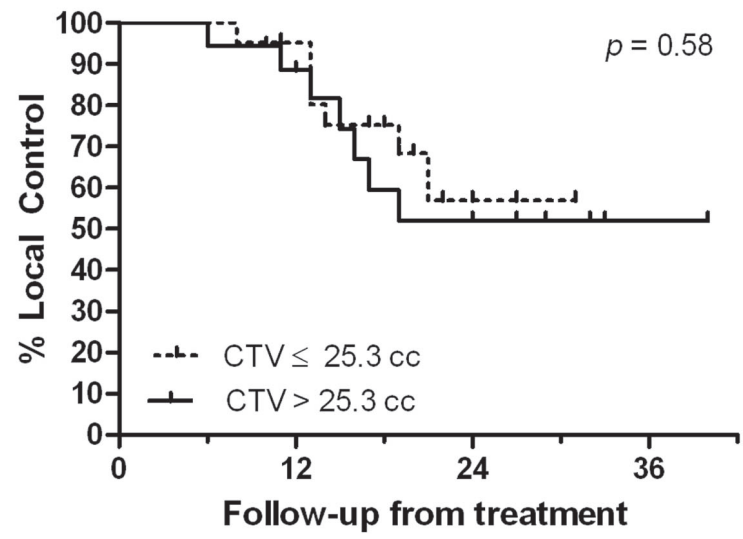

\# tumors at risk

$\begin{array}{lllrrrrr}\mathrm{CTV} \leq & 21 & 21 & 19 & 12 & 3 & 1 & 0 \\ \mathrm{CTV}> & 18 & 18 & 15 & 9 & 7 & 5 & 3\end{array}$

C

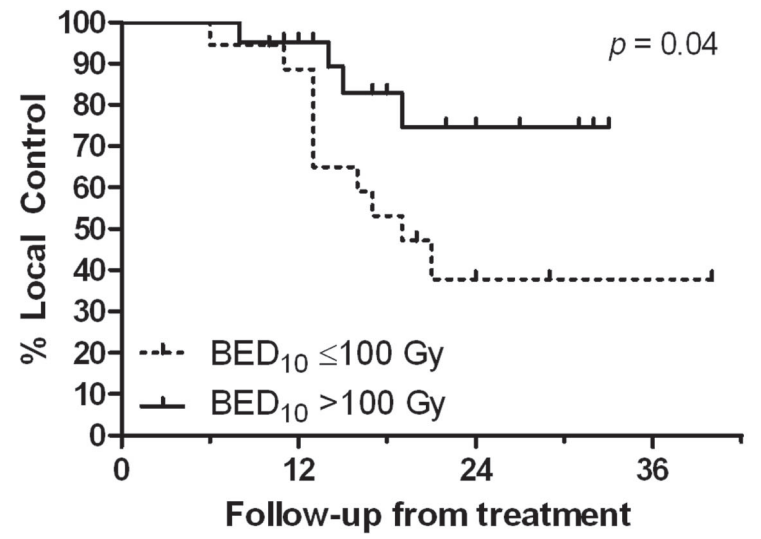

\# tumors at risk

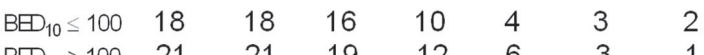

$\begin{array}{llllllll}\mathrm{BE}_{10}>100 & 21 & 21 & 19 & 12 & 6 & 3 & 1\end{array}$

FIGURE 2 | Local control analysis (A) from time of SBRT.

(B) Comparison of local control for tumors with a CTV $\leq 25.3 \mathrm{cc}$ to those with a CTV $>25.3 \mathrm{cc}$. (C) Comparison of local control for those tumors receiving a BED10 of $\leq 100$ Gy10 to those receiving a BED10 > 100 Gy10. 

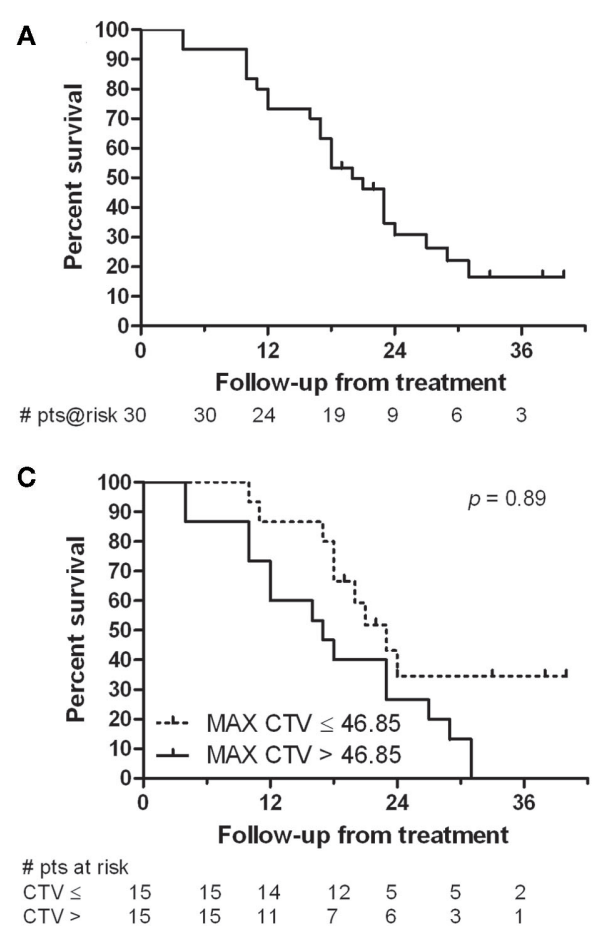

FIGURE 3 | Survival analysis (A) from time of SBRT and (B) from time of diagnosis. (C) Comparison of overall survival for patients with a largest CTV $\leq 46.85 \mathrm{cc}$ to those with a largest CTV

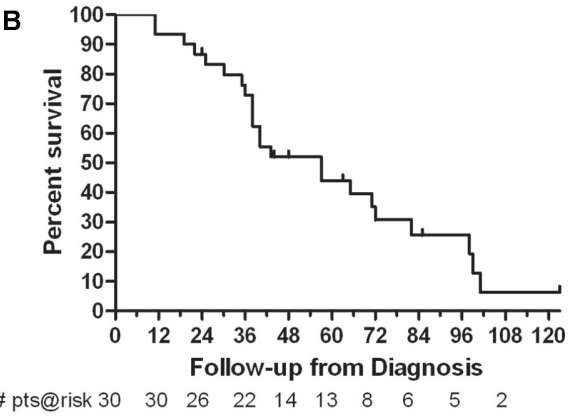

D

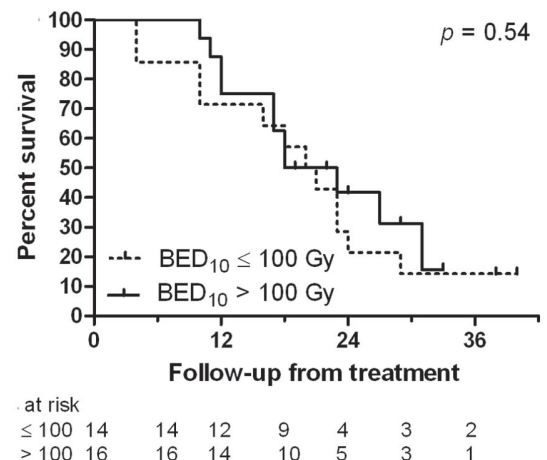

$>46.85$ cc. (D) Comparison of overall survival for those patients receiving a BED10 of $\leq 100$ Gy10 to those receiving a BED10 > 100 Gy10. of treatment are included in this analysis. The patient retreated for local failure received two courses of SBRT, each $45 \mathrm{~Gy} \times 3 \mathrm{fx}$. At last follow-up by PET/CT, this patient has local control in the treated lesion, but new distant liver metastases. Five months after retreatment, he had grade 2 toxicity consisting of abdominal pain, inflammation of the second portion of the duodenum and pelvic fluid by CT scan, but these SBRT related symptoms resolved within 7 months of retreatment.

\section{DISCUSSION}

While SBRT for liver metastases and primary tumors is a relatively new concept, a large body of retrospective literature is available describing early treatment results (Hoyer et al., 2006; Mendez Romero et al., 2006; Wulf et al., 2006; Lee et al., 2009; Rusthoven et al., 2009; van der Pool et al., 2010; Chang et al., 2011; Vautravers-Dewas et al., 2011) including four prospective Phase I studies (Schefter et al., 2005; Lee et al., 2009; Goodman et al., 2010; Rule et al., 2011). The earliest phase I trial reported by Schefter et al. (2005) established the benefit and safety of SBRT for liver metastases with eligible patients having 1-3 lesions, tumor diameters $<6 \mathrm{~cm}$, and adequate liver function. Dose limiting toxicity was not found despite escalation to $60 \mathrm{~Gy}$ in 3 fractions. Dose volume constraints ensured at least $700 \mathrm{cc}$ of uninvolved liver received $<15 \mathrm{~Gy}$. When we began SBRT this was the only published prospective study, however, early retrospective series (Hoyer et al., 2006; Mendez Romero et al., 2006; Wulf et al., 2006; Lee et al., 2009) were available which helped to initiate our program in 2007. Based on these studies, our initial dose fractionation schema was $12.5 \mathrm{~Gy} \times 3$ fractions. As our experience and the literature matured, we progressively increased dose. Because of the dose prescription variability in this series, a dose response analysis was possible which documented increased local control for a BED > 100 Gy10. McCammon et al. (2009) reviewed their lung and liver experience with stereotactic radiation and found a dose response with increased nominal dose of 54 Gy or greater in 3 fractions. Their 3-year actuarial local control rate was $89.3 \%$ for a dose $>54 \mathrm{~Gy}$ compared to 59 and $8.1 \%$ for those treated to $36-53.9$ Gy and $<36$ Gy, respectively. Rule et al. (2011) revealed improved local control of $100 \%$ at 2 years in a phase I trial with dose escalation to $60 \mathrm{~Gy}$ in 5 fractions for liver metastases compared to $56 \%$ local control with $30 \mathrm{~Gy}$ in 3 fractions. A pooled analysis of patients treated with SBRT for colorectal liver metastases from Stanford University, Princess Margaret Hospital and University of Colorado revealed total dose, dose per fraction and BED to be significant for local control by lesion in multivariate analysis. They estimated a dose of $46-54$ Gy in 3 fractions or a BED of 117 Gy10 (EQD2 = 98 Gy) would be required for 1 -year local control rates $>90 \%$ (Chang et al., 2011). VautraversDewas et al. (2011) did not demonstrate a dose response in 42 patients with 62 metastases, however, their dose prescription was limited to $40 \mathrm{~Gy}$ in 4 fractions and $45 \mathrm{~Gy}$ in 3 fractions (BED 80-113 Gy10, EQD2 = 66-94 Gy). The current series is consistent with the above literature which confirms adequate dose is required for local control with a BED > 100 Gy10 (EQD2 = 90 Gy) suggested. However, given the mixed population of primary and metastatic tumors combined with a range of primary tissue types, 
further study is necessary to determine the optimal BED based on histology.

Observed toxicities in the current study were generally mild with only one patient experiencing grade 3 or greater toxicity without recurrent disease which could account for the toxicity. This patient with a solitary liver metastases adjacent to ribs developed rib pain and fracture 19 months following SBRT. Extrapolating from the SBRT lung literature reveals that rib fractures are the most common late toxicity from SBRT (Pettersson et al., 2009; Nambu et al., 2011). Thus, while treating liver metastases with SBRT generally does not require contouring of the ribs, we recommend contouring those cases where the liver lesion resides within $2 \mathrm{~cm}$ of the rib using suitable dose constraints (Pettersson et al., 2009).

One would expect tumor size to be a significant prognosticator for local control based on basic radiobiologic principles; however the SBRT literature does not support this concept. In the pooled experience reported by Chang et al. (2011), tumor size did not predict local control in multivariate analysis. Tumor size was not predictive of local control in the series by
Vautravers-Dewas et al. (2011) who analyzed local control for tumor sizes less than or greater than $25 \mathrm{~mm}$. Our series, as well, revealed no significant tumor size effect in univariate analysis, suggesting that high-dose SBRT can overcome the decrease in local control usually seen with increased tumor volume after protracted fractionation conventional radiotherapy.

Assessment of local control following SBRT has historically included CAT scan, MRI scan, and more recently PET/CT. Limitations exist with anatomic tumor response metrics using CT and MRI including WHO criteria, RECIST and RECIST 1.1 which depend on tumor size change. Also it is known that the sensitivity and specificity for detection of liver metastases and local liver recurrence improves with PET/CT compared to CT scanning (Patel et al., 2011). The current series depended heavily on PET/CT for local control assessment (Table 2). The benefit of PET/CT is not only that anatomic change is visualized and size is measured, but that the metabolic tumor activity can also be assessed and compared to pretreatment. In the current experience, the authors believe there is less ambiguity with increased confidence regarding coding of local control and failure with PET/CT. The

Table 3 | Review of stereotactic body radiation therapy for liver metastases and liver tumors.

\begin{tabular}{|c|c|c|c|c|c|c|c|}
\hline Author & $\begin{array}{l}\text { Number of } \\
\text { Primary/Met } \\
\text { patients }\end{array}$ & Dose (Gy) & $\begin{array}{l}\text { BED Gy10 } \\
\text { (EQD2) }\end{array}$ & $\begin{array}{l}\text { Median } \\
\text { follow-up } \\
\text { (months) }\end{array}$ & $\begin{array}{l}\text { Local } \\
\text { control } \\
\text { evaluation }\end{array}$ & $\begin{array}{l}2 \text { year } \\
\text { local } \\
\text { control }\end{array}$ & $\begin{array}{l}2 \text { year } \\
\text { overall } \\
\text { survival }\end{array}$ \\
\hline Wulf et al. (2006) & $5 / 39$ & $\begin{array}{l}26-37.5 \mathrm{~Gy} / \\
1-4 \mathrm{fx}\end{array}$ & $\begin{array}{l}48-93 \\
(40-78)\end{array}$ & 15 & CT/MRI & $\begin{array}{l}66 \% \\
82 \% \\
\text { BED }>79\end{array}$ & $32 \%$ \\
\hline Ambrosino et al. (2009) & 27 mets & $\begin{array}{l}\text { med } 36 \text { Gy/3 } \\
\text { fx (25-60 Gy) }\end{array}$ & $79.2(66)$ & 13 & $\mathrm{CT}$ & $74 \%^{\ddagger}$ & $93 \%$ crude \\
\hline Rusthoven et al. (2009) & 47 mets & $\begin{array}{l}36-60 \mathrm{~Gy} \\
60 \mathrm{~Gy} / 3 \mathrm{fx}\end{array}$ & $\begin{array}{l}79.2- \\
180 \\
(66-150)\end{array}$ & 16 & $\mathrm{CT} / \mathrm{MRI}$ & $92 \%$ & $30 \%$ median $20.5 \mathrm{~m}$ \\
\hline Lee et al. (2009) & 68 mets & $\begin{array}{l}\text { Median } \\
41.8 \mathrm{~Gy} / 6 \mathrm{fx}\end{array}$ & $\begin{array}{l}36-120 \\
(30-100)\end{array}$ & 10.8 & $\mathrm{CT} / \mathrm{MRI}$ & $71 \%{ }^{\dagger}$ & $\begin{array}{l}47 \% \text { at } 18 \mathrm{~m} \text { median } \\
17.6 \mathrm{~m}\end{array}$ \\
\hline Chang et al. (2011) & $\begin{array}{l}65 \text { colorectal } \\
\text { mets }\end{array}$ & $\begin{array}{l}\text { Median } 42 \text { Gy } \\
\text { 22-60 Gy/ } \\
1-6 \mathrm{fx}\end{array}$ & $\begin{array}{l}82-120 \\
(68-100)\end{array}$ & 14.4 & $\begin{array}{l}\text { CT/MRI, } \\
\text { PET/CT }\end{array}$ & $\begin{array}{l}55 \% \\
71 \% \\
\text { BED > } 79\end{array}$ & $38 \%$ \\
\hline Goodman et al. (2010) & $7 / 19$ & $18-30 \mathrm{~Gy} / 1 \mathrm{fx}$ & $\begin{array}{l}50-120 \\
(42-100)\end{array}$ & 17.3 & $\begin{array}{l}\mathrm{PET} / \mathrm{CT} \\
\mathrm{CT}, \mathrm{MRI}\end{array}$ & $77 \%{ }^{\dagger}$ & $50.4 \%$ median $28.6 \mathrm{~m}$ \\
\hline Stintzing et al. (2010) & $4 / 32$ & $24 \mathrm{~Gy} / 1 \mathrm{fx}$ & $81.6(68)$ & 21.3 & $\mathrm{MRI}$ & $86 \%$ & $62 \%$ median $25.1 \mathrm{~m}$ \\
\hline van der Pool et al. (2010) & $\begin{array}{l}20 \text { colorectal } \\
\text { mets }\end{array}$ & $\begin{array}{l}37.5 \mathrm{~Gy} / 3 \mathrm{fx}, \\
45 \mathrm{~Gy} / 3 \mathrm{fx}\end{array}$ & $\begin{array}{l}84.4 \\
112.5\end{array}$ & 26 & CT/MRI & $74 \%$ & 83\% median 34 m \\
\hline Rule et al. (2011) & 27 mets & $\begin{array}{l}30 \mathrm{~Gy} / 3 \mathrm{fx} \\
50 \mathrm{~Gy} / 5 \mathrm{fx} \\
60 \mathrm{~Gy} / 5 \mathrm{fx}\end{array}$ & $\begin{array}{l}60,100 \\
132\end{array}$ & 20 & $\mathrm{CT} / \mathrm{MRI}$ & $\begin{array}{l}56,89 \\
100 \% \text { for } \\
30-, 50- \\
\text { and } 60-G y\end{array}$ & $\begin{array}{l}50,67,56 \% \text { for } 30- \\
50-\text { and } 60-G y, \text { median } \\
37 \mathrm{~m}\end{array}$ \\
\hline Vautravers-Dewas et al. (2011) & 42 mets & $\begin{array}{l}40 \mathrm{~Gy} / 4 \mathrm{fx} \\
45 \mathrm{~Gy} / 3 \mathrm{fx}\end{array}$ & $\begin{array}{l}80-113 \\
(66-94)\end{array}$ & 14.3 & $\mathrm{CT}, \mathrm{MRI}$ & $86 \%$ & $48 \%$ \\
\hline Lanciano et al. (this article) & $7 / 23$ & $\begin{array}{l}36-60 \mathrm{~Gy} / 3 \\
\mathrm{fx}, 50 \mathrm{~Gy} / 5 \mathrm{fx}\end{array}$ & $\begin{array}{l}79.2- \\
180 \\
(66-150)\end{array}$ & 22 & $\begin{array}{l}\mathrm{PET} / \mathrm{CT} \\
\mathrm{CT} \text { or } \\
\mathrm{MRI}\end{array}$ & $\begin{array}{l}57 \%, \\
75 \% \\
\text { BED10 } \\
>100 \mathrm{~Gy}\end{array}$ & $\begin{array}{l}31 \%, 42 \% \\
\text { BED } 10>100 \mathrm{~Gy} \\
\text { median } 20 \mathrm{~m}\end{array}$ \\
\hline
\end{tabular}

${ }^{+} 1$ year local control; ${ }^{\ddagger} 1$ year crude local control; fx, fractions; OS, overall survival. 
proposed PET/CT response criterion (PERCIST) would require a $30 \%$ decline in SUV for response with complete response reserved for resolution of metabolic activity (Wahl et al., 2009).

As shown in Table 3, local control rates are excellent with SBRT, however, follow-up is short and most series include a heterogeneous group of patients with variable tumor types and volume, previous treatment, liver size, and liver disease status. The experience of Hoyer et al. (2006) demonstrates long term survival is possible with SBRT for liver/lung metastases from colorectal cancer with $86 \%$ local control at 2 years and 13\% 5-year survival for a group of patients who were unresectable at presentation. However, questions remain regarding how to define the CTV after chemotherapy, the margins needed around the CTV, and benefit of additional diagnostic studies for treatment planning. CT with contrast is used for treatment planning, but the value of MRI and PET/CT to improve target definition and optimal merging of these images with CT requires further research. Treatment margins vary in the literature, usually ranging from 5 to $15 \mathrm{~mm}$ for non-CyberKnife series and 3-10 mm for CyberKnife series, where motion tracking allows for smaller margins. Any dose comparison must include the prescription point (for our series generally $5 \mathrm{~mm}$ margins were used and dose prescribed to the $60-80 \%$ isodose to cover $95 \%$ of the PTV) since margins vary from series-to-series making conclusions regarding dose response difficult. Homogeneous series of patients with liver metastases in multi-institutional trials treated on standard protocols are needed to further refine dose volume relationships, effect on local control and ultimately survival. An international phase II study of CyberKnife SBRT, sponsored by Accuray International, for hepatic metastases from

\section{REFERENCES}

Adam, R., Wicherts, D. A., De Haas, R. J., Ciacio, O., Levi, F., Paule, B., Ducreux, M., Azoulay, D., Bismuth, H., and Castaing, D. (2009). Patients with initially unresectable colorectal liver metastases: is there a possibility of cure? J. Clin. Oncol. 27, 1829-1835.

Ambrosino, G., Polistina, F., Costantin, G., Francescon, P., Guglielmi, R., Zanco, P., Casamassima, F., Febbraro, A., Gerunda, G., and Lumachi, F. (2009). Image-guided robotic stereotactic radiosurgery for unresectable liver metastases: preliminary results. Anticancer Res. 29, 3381-3384.

Chang, D. T., Swaminath, A., Kozak, M., Weintraub, J., Koong, A. C., Kim, J., Dinniwell, R., Brierley, J., Kavanagh, B. D., Dawson, L. A., and Schefter, T. E. (2011). Stereotactic body radiotherapy for colorectal liver metastases: a pooled analysis. Cancer 117, 4060-4069.

Choi, B. O., Choi, I. B., Jang, H. S., Kang, Y. N., Jang, J. S., Bae, S. H., Yoon, S. K., Chai, G. Y., and Kang, K. M. (2008). Stereotactic body radiation therapy with or without transarterial chemoembolization for patients with primary hepatocellular carcinoma: preliminary analysis. BMC Cancer 8, 351. doi:10.1186/1471-2407-8-351

Cox, J. D., Stetz, J., and Pajak, T. F. (1995). Toxicity criteria of the Radiation Therapy Oncology Group (RTOG) and the European Organization for Research and Treatment of Cancer (EORTC). Int. J. Radiat. Oncol. Biol. Phys. 31, 1341-1346.

Goodman, K. A., Anderson, E. M., Maturen, K. E., Zhang, Z., Mo, Q., Yang, G., Gibbs, I. C., Fisher, G. A., and Koong, A. C. (2010). Dose escallation study of stereotactic body radiotherapy for liver malignancies. Int. J. Radiat. Oncol. Biol. Phys. 78, 486-493.

Hoyer, M., Roed, H., Traberg Hansen, A., Ohlhuis, L., Petersen, J., Nellemann, H., Kiil Berthelsen, A., Grau, C., Aage Engelholm, S., and Von Der Maase, H. (2006). Phase II study on stereotactic body radiotherapy of colorectal metastases. Acta Oncol. 45, 823-830.

Kemeny, N. (2006). Management of liver metastases from colorectal cancer. Oncology (Williston Park, N.Y.) 20, 1161-1176, 1179; discussion 1179-1180, 1185-1166.

colorectal cancer is currently open and enrolling patients (ClinicalTrials.gov access number NCT01318447). The study is restricted to patients with 1-3 colorectal metastases with a cumulative tumor volume of $<10 \mathrm{~cm}$ and delivers $45 \mathrm{~Gy}$ in 3 fractions to the PTV with $8 \mathrm{~mm}$ margin on GTV. Tumor control assessment will include CT/MRI and PET/CT.

\section{CONCLUSION}

CyberKnife SBRT is an effective modality with good local control and low morbidity for metastatic disease to the liver or for primary liver tumors which are unresectable or medically inoperable. The current dose response analysis suggests that a dose $>100$ Gy10 is necessary for optimal local control, however further study is necessary to evaluate the dose response for primary and metastatic lesions based on histology. Early detection of metastatic disease with smaller tumor volume would ensure high doses of SBRT could be delivered safely and improve the chances for local control and dose escalation. Future study is necessary to examine the use of SBRT in combination with chemotherapy in a multimodality program since metastatic disease remains the primary pattern of failure.

\section{ACKNOWLEDGMENTS}

We gratefully acknowledge the numerous helpful discussions and encouragement provided by Jack Fowler, Ph. D., as well as the editorial assistance of Pam Commike, Ph.D., Accuray Incorporated. The views expressed here are entirely the authors'; Accuray did not provide assistance with data collection, compilation, or interpretation.

Kilby, W., Dooley, J. R., Kuduvalli, G., Sayeh, S., and Maurer, C. R. Jr. (2010). The CyberKnife robotic radiosurgery system in 2010. Technol. Cancer Res. Treat. 9, 433-452.

Lee, M. T., Kim, J. J., Dinniwell, R., Brierley, J., Lockwood, G., Wong, R., Cummings, B., Ringash, J., Tse, R. V., Knox, J. J., and Dawson, L. A. (2009). Phase I study of individualized stereotactic body radiotherapy of liver metastases. J. Clin. Oncol. 27, 1585-1591.

Louis, C., Dewas, S., Mirabel, X., Lacornerie, T., Adenis, A., Bonodeau, F., and Lartigau, E. (2010). Stereotactic radiotherapy of hepatocellular carcinoma: preliminary results. Technol. Cancer Res. Treat. 9, 479-487.

McCammon, R., Schefter, T. E., Gaspar, L. E., Zaemisch, R., Gravdahl, D., and Kavanagh, B. (2009). Observation of a dose-control relationship for lung and liver tumors after stereotactic body radiation therapy. Int. J. Radiat. Oncol. Biol. Phys. 73, 112-118.

Mendez Romero, A., Wunderink, W., Hussain, S. M., De Pooter, J. A., Heijmen, B. J., Nowak, P. C., Nuyttens, J.
J., Brandwijk, R. P., Verhoef, C., Ijzermans, J. N., and Levendag, P. C. (2006). Stereotactic body radiation therapy for primary and metastatic liver tumors: a single institution phase i-ii study. Acta Oncol. 45, 831-837.

Nambu, A., Onishi, H., Aoki, S., Koshiishi, T., Kuriyama, K., Komiyama, T., Marino, K., Araya, M., Saito, R., Tominaga, L., Maehata, Y., Sawada, E., and Araki, T. (2011). Rib fracture after stereotactic radiotherapy on follow-up thin-section computed tomography in 177 primary lung cancer patients. Radiat. Oncol. 6, 137.

Patel, S., Mccall, M., Ohinmaa, A., Bigam, D., and Dryden, D. M. (2011). Positron emission tomography/computed tomographic scans compared to computed tomographic scans for detecting colorectal liver metastases: a systematic review. Ann. Surg. 253, 666-671.

Pettersson, N., Nyman, J., and Johansson, K.A. (2009). Radiation-induced rib fractures after hypofractionated stereotactic body radiation therapy of non-small cell lung cancer: a dose- and volume-response analysis. Radiother. Oncol. 91, 360-368. 
Robertson, D. J., Stukel, T. A., Gottlieb, D. J., Sutherland, J. M., and Fisher, E. S. (2009). Survival after hepatic resection of colorectal cancer metastases: a national experience. Cancer $115,752-759$.

Rule, W., Timmerman, R., Tong, L., Abdulrahman, R., Meyer, J., Boike, T., Schwarz, R. E., Weatherall, P., and Chinsoo Cho, L. (2011). Phase I dose-escalation study of stereotactic body radiotherapy in patients with hepatic metastases. Ann. Surg. Oncol. 18, 1081-1087.

Rusthoven, K. E., Kavanagh, B. D., Cardenes, H., Stieber, V. W., Burri, S. H., Feigenberg, S. J., Chidel, M. A., Pugh, T. J., Franklin, W., Kane, M., Gaspar, L. E., and Schefter, T. E. (2009). Multi-institutional phase I/II trial of stereotactic body radiation therapy for liver metastases. J. Clin. Oncol. 27, 1572-1578.

Schefter, T. E., Kavanagh, B. D., Timmerman, R. D., Cardenes, H. R., Baron, A., and Gaspar, L. E. (2005). A phase I trial of stereotactic body radiation therapy (SBRT) for liver metastases.
Int. J. Radiat. Oncol. Biol. Phys. 62, 1371-1378.

Stintzing, S., Hoffmann, R. T., Heinemann, V., Kufeld, M., and Muacevic, A. (2010). Frameless singlesession robotic radiosurgery of liver metastases in colorectal cancer patients. Eur. J. Cancer 46, 1026-1032.

Therasse, P., Arbuck, S. G., Eisenhauer, E. A., Wanders, J., Kaplan, R. S., Rubinstein, L., Verweij, J., Van Glabbeke, M., Van Oosterom, A. T., Christian, M. C., and Gwyther, S. G. (2000). New guidelines to evaluate the response to treatment in solid tumors. European Organization for Research and Treatment of Cancer, National Cancer Institute of the United States, National Cancer Institute of Canada. J. Natl. Cancer Inst. 92, 205-216.

Timmerman, R. D. (2008). An overview of hypofractionation and introduction to this issue of seminars in radiation oncology. Semin. Radiat. Oncol. 18, 215-222. van der Pool, A. E., Mendez Romero, A., Wunderink, W., Heijmen, B. J., Levendag, P. C., Verhoef, C., and Ijzermans, J. N. (2010). Stereotactic body radiation therapy for colorectal liver metastases. Br. J. Surg. 97, 377-382.

Vautravers-Dewas, C., Dewas, S., Bonodeau, F., Adenis, A., Lacornerie, T., Penel, N., Lartigau, E., and Mirabel, X. (2011). Image-guided robotic stereotactic body radiation therapy for liver metastases: is there a dose response relationship? Int. J. Radiat. Oncol. Biol. Phys.

Wahl, R. L., Jacene, H., Kasamon, Y., and Lodge, M. A. (2009). From RECIST to PERCIST: evolving considerations for PET response criteria in solid tumors. J. Nucl. Med. 50(Suppl. 1), 122S-150S.

Wulf, J., Guckenberger, M., Haedinger, U., Oppitz, U., Mueller, G., Baier, K., and Flentje, M. (2006). Stereotactic radiotherapy of primary liver cancer and hepatic metastases. Acta Oncol 45, 838-847.
Conflict of Interest Statement: Rachelle Lanciano has received honoraria from Accuray, Inc., for CME related presentations relating to use of the CyberKnife.

Received: 06 January 2012; paper pending published: 19 January 2012; accepted: 19 February 2012; published online: 09 March 2012.

Citation: Lanciano R, Lamond J, Yang $J$, Feng J, Arrigo S, Good $M$ and Brady L (2012) Stereotactic body radiation therapy for patients with heavily pretreated liver metastases and liver tumors. Front. Oncol. 2:23. doi: 10.3389/fonc. 2012.00023

This article was submitted to Frontiers in Radiation Oncology, a specialty of Frontiers in Oncology.

Copyright (c) 2012 Lanciano, Lamond, Yang, Feng, Arrigo, Good and Brady.

This is an open-access article distributed under the terms of the Creative Commons Attribution Non Commercial License, which permits non-commercial use, distribution, and reproduction in other forums, provided the original authors and source are credited. 